\title{
EGFR NP_005219.2:p.Y764_V765insHH
}

National Cancer Institute

\section{Source}

National Cancer Institute. EGFR NP 005219.2:p.Y764 V765insHH. NCI Thesaurus. Code C98604.

An insertion of the amino acid sequence histidine-histidine between the tyrosine at position 764 and the valine at position 765 of the epidermal growth factor receptor protein. 